\title{
Multi-criteria Ranking Under Pareto Inclusive Criterion of Preference: An Application in Ranking Some Fungi Species with Respect to Their Toxicity
}

\author{
Agnieszka Gniadek ${ }^{1}$, Izabela Chmiel $^{1}$, Maciej Górkiewicz $^{1}$ \\ ${ }^{1}$ Faculty of Health Sciences, Jagiellonian University Medical College, Krakow, Poland
}

\begin{abstract}
This study aims at demonstrating the usefulness of the Pareto inclusive criterion methodology for comparative analyses of fungi toxicity. The toxicity of fungi is usually measured using a scale of several ranks. In practice, the ranks of toxicity are routinely grouped into only four conventional classes of toxicity: from a class of no toxicity, low toxicity, and moderate toxicity, to a class of high toxicity. The illustrative material included the $\mathrm{N}=61$ fungi samples obtained from three species: A. ochraceus, A. niger and A. flavus. In accordance with the Pareto approach, four partial criterions of the worst toxicity were defined, a single criterion used for each conventional class of toxicity. Finally, the odds ratios (OR) were calculated separately for each partial criterion, and the significance of the hypotheses $\mathrm{OR}=1$ was estimated. It was stated that A. ochraceus fungi are distinctly more toxic than the two remaining ones with respect to the all considered four partial criterions, with significance equal to $\mathrm{p}=0.04, \mathrm{p}=0.04, \mathrm{p}=0.007$ and $\mathrm{p}=0.005$, respectively. Thus, the suggested method illustrated its utility in the case under study.
\end{abstract}

\section{Introduction}

The current literature does not provide convincing information concerning the level of exposure to toxigenic fungi that is measurably dangerous to human health. It has been demonstrated that in laboratory conditions mycotoxins have cytotoxic activity (Aziz, 2006; Byun et al., 2008; Gniadek et al., 2010, 2011). Secondary metabolites of mould fungi include mycotoxins, which act on living mutagenic or carcinogenic cells. The most toxic fungi are considered to be the ones belonging to the species such as Aspergillus, Stachybotrys or Fusarium (Gniadek, 2012). In medicine, the best-known mycotoxins are aflatoxins, ochratoxins and trichothecenes. Assessment of the cytotoxicity of species of various fungi can include general and/or quantitative assessment (Gareis, 1994). For general assessment, the MTT test is used 
(Aziz, 2006; Byun et al., 2008). The evaluation is determined by conversion of yellow tetrazolium salt MTT into purple, insoluble in water formazan by metabolically active cells, intact by fungi toxins. Only metabolically active cells can carry out this process. For tests sensitive to the majority of toxins, swine kidney cells can be used. The reduction of MTT to formazan proceeds proportionally to the number of metabolically active cells. Thus, the stronger the staining of swine kidney cells, the stronger the cytotoxicity of the fungi species that infected them.

In this study, the data from routine measurements of toxicity of fungi in hospital wards were used to demonstrate the practical usefulness of using a multi-criteria approach based on the Pareto inclusive criterion in the comparative analyses of fungi toxicity.

The Pareto inclusive criterion imitates the natural process of looking for the best alternative (Czyżak et al., 1998). It takes into account several partial criterions, but each partial criterion is proved separately from the others, and in this way the worst (or the best) sample can be defined, if any (Czyżak et al., 1998). Therefore, the procedure of the Pareto approach includes multiple steps of pair-wise comparisons involving only a single partial criterion at each step.

Generally, the task of multi-criteria choice arises in a situation, if from some limited set of objects $\left\{O_{i}\right\}, i=1,2, \ldots, N<\infty$, the single worst (or on the contrary, the single best) object should be chosen with the best possible fit to some given set of the partial criteria of preference $\left\{C_{m}\right\}$, $m=1,2, \ldots, M<\infty$. It is assumed that under each considered partial criterion, each pair of objects under consideration is linked with only one single relation out of three possible relations:

either $\left(O_{j}\right.$ is better than $\left.O_{k}\right),\left(O_{j}\right.$ is worse than $\left.O_{k}\right)$ or else $\left(O_{j}\right.$ is equal to $\left.O_{k}\right), O_{j}, O_{k} \in\left\{O_{i}\right\}$.

The Pareto inclusive criterion takes into account all $M$ partial criteria from the given set $\left\{C_{m}\right\}, m=1,2, \ldots, M$, in such a way that it recognises the worst object $O_{w} \in\left\{O_{i}\right\}$ only if this object fulfils the condition:

[ $\left(O_{w}\right.$ is worse than $\left.O_{k}\right)$ or $\left(O_{j}\right.$ is equal to $\left.\left.O_{k}\right)\right]$ with respect to each partial criterion $C_{m} \in\left\{C_{m}\right\}, m=1,2, \ldots, M, O_{j}, O_{k} \in\left\{O_{i}\right\}$; with at least a single decisive relation $\left(O_{w}\right.$ is worse than $\left.O_{k}\right)$.

If the need arises, the Pareto inclusive criterion can be applied with the aim of recognising the best object in an analogous way, but with use of the "better than" relations instead of "worse than" (Fernández et al., 2001). 
The rest of this paper includes descriptions of the measuring procedure and distribution of the assessed toxicity. The presented results include the descriptive statistics of the data and the results of the multi-criteria comparisons with the Pareto inclusive criterion, with a general conclusion that the proposed method showed its utility in the case under study. Finally, the strengths and weaknesses of the proposed methodology are discussed.

\section{Measuring Cytotoxicity of the Fungi}

For quantitative assessment of the cytotoxicity of the fungi of the $A s$ pergillus species, a microtubular spectrophotometer (reader Elisa digiscan of the firm Asys Hitech GmbH, Austria) and the Mikro Win 2000 program (firm Mikrotek Laborsysteme GmbH, Germany) were used. The measurement was performed at a wavelength of $510 \mathrm{~nm}$, and on the basis of dilution. The boundary toxic concentration, that is the smallest tested sample in $\left[\mathrm{cm}^{2} / \mathrm{ml}\right]$ which caused toxic action on the cells (Mean Inhibitory Concentration), was determined and then interpreted as the conventional weight of toxicity of the fungi under examination.

The classes of toxicity were defined according to the conventional weights of toxicity (Gareis, 1994):

If $(31.251 \leq$ the conventional weight) then (class: no toxicity);

If (7.813 $\leq$ the conventional weight 31.25$)$ then (class: low toxicity);

If $(0.977 \leq$ the conventional weight 3.906$)$ then (class: moderate toxicity);

If $(0.061 \leq$ the conventional weight 0.488$)$ then (class: high toxicity).

\section{Material}

The data set under study included $N=61$ observations of the conventional weights of fungi toxicity, made using A. ochraceus fungi species (28 observations), A. niger fungi (22 observations), and A. flavus fungi species (11 observations). These data were grouped into four classes of fungi toxicity: no toxicity, low toxicity, moderate toxicity, and high toxicity (Gareis, 1994). Table 1 shows the found frequencies of the conventional weights of the toxicity at each class of toxicity, as measured in the set of $N=61$ fungi samples drawn from the three fungi species under study. 
Agnieszka Gniadek, Izabela Chmiel, Maciej Górkiewicz

Table 1. The data under study: distribution of the measured toxicity

\begin{tabular}{|c|c|c|c|c|}
\hline \multicolumn{2}{|c|}{ Toxicity } & \multicolumn{3}{|c|}{ Fungi species } \\
\hline Class & Weight & A. ochraceus & A. niger & A. flavus \\
\hline \multirow[t]{4}{*}{ high } & 0.061 & 4 & 0 & 0 \\
\hline & 0.122 & 3 & 0 & 0 \\
\hline & 0.244 & 2 & 1 & 1 \\
\hline & 0.488 & 2 & 2 & 0 \\
\hline \multicolumn{2}{|c|}{ total high } & 11 & 3 & 1 \\
\hline \multirow[t]{3}{*}{ moderate } & 0.977 & 6 & 0 & 0 \\
\hline & 1.953 & 2 & 2 & 1 \\
\hline & 3.906 & 3 & 0 & 2 \\
\hline \multicolumn{2}{|c|}{ total moderate } & 11 & 2 & 3 \\
\hline \multirow[t]{3}{*}{ low } & 7.813 & 1 & 2 & 0 \\
\hline & 15.625 & 0 & 4 & 3 \\
\hline & 31.25 & 3 & 2 & 2 \\
\hline \multicolumn{2}{|c|}{ total low } & 4 & 8 & 5 \\
\hline no & 31.251 & 2 & 9 & 2 \\
\hline \multicolumn{2}{|c|}{ total all classes } & 28 & 22 & 11 \\
\hline
\end{tabular}

\section{Method}

The equality of the distribution of the four classes of toxicity was examined with the classical chi-square test for the given table of frequencies. In accordance with the Pareto approach, the four partial criterions for detecting the worst sample were defined, a single criterion for each class of toxicity:

$1^{\text {st }}$ partial criterion for the class of no toxicity:

The worst sample has the lowest chance of being a member of the no toxicity class;

$2^{\text {nd }}$ partial criterion for the class of high toxicity:

The worst sample has the greatest chance of being a member of the high toxicity class;

$3^{\text {rd }}$ partial criterion for the class of low toxicity:

The worst sample has a lower chance of being a member of the low toxicity class than of being a member of the moderate or high toxicity classes; 
Multi-criteria Ranking Under Pareto Inclusive Criterion of Preference...

$4^{\text {th }}$ partial criterion for the class of moderate toxicity:

The worst sample has a greater chance of being a member of the moderate toxicity class than of being a member of the no toxicity or low toxicity classes.

Under the Pareto approach, the procedure of the odds ratios (OR) provide a basis for estimations of the significance of the hypotheses $\mathrm{OR}=1$, because for any given table of frequencies, the variance of the $\ln (\mathrm{OR})$ can be easily estimated. The final stage of the odds ratio procedure in this study can be considered as the series of four z-tests for the estimated values and variances of $\ln (\mathrm{OR})$ and the assumed mean value $\ln (\mathrm{OR})=0$.

\section{Results}

The empirical distributions of the four classes of toxicity (no toxicity, low toxicity, moderate toxicity, high toxicity) are shown separately for each fungi species under study in Table 2. As illustrated there, the classical chisquare test gave clear reason to reject the composite null hypothesis: the three distributions under study did not differ significantly, with significance $p=0.004<0.05 ;$ where $p=0.05$ was the assumed reference level.

\section{Table 2. Frequencies of the toxicity classes in all three fungi under study}

\begin{tabular}{|c|c|c|c|c|c|c|}
\hline \multirow{3}{*}{ Toxicity class } & \multicolumn{6}{|c|}{ Fungi species } \\
\hline & \multicolumn{2}{|c|}{ A. ochraceus } & \multicolumn{2}{|c|}{ A. niger } & \multicolumn{2}{|c|}{ A. flavus } \\
\hline & $N_{1}$ & $\%$ & $N_{2}$ & $\%$ & $N_{3}$ & $\%$ \\
\hline no toxicity & 2 & 7.1 & 9 & 40.9 & 2 & 18.2 \\
\hline low & 4 & 14.3 & 8 & 36.4 & 5 & 45.5 \\
\hline moderate & 11 & 39.3 & 2 & 9.1 & 3 & 27.3 \\
\hline high & 11 & 39.3 & 3 & 13.6 & 1 & 9.1 \\
\hline Total & 28 & 100.0 & 22 & 100.0 & 11 & 100.0 \\
\hline \multicolumn{7}{|c|}{$\begin{array}{l}\text { Chi-square test: } p=0.004 \text {; conclusion: the distributions of the classes } \\
\text { of toxicity were significantly varied in the three fungi species under } \\
\text { study }\end{array}$} \\
\hline
\end{tabular}

Table 3 shows the observed frequencies of the toxicity classes for only two fungi species, A. niger fungi species versus A. flavus species. When comparing the observed frequencies of toxicity between those species, the classical chi-square test gave clear reason to accept the null hypothesis: 
the two compared distributions did not differ significantly, with significance $p=0.39>0.05$; where $p=0.05$ was the assumed reference level.

Table 3. Frequencies of the toxicity classes of only two fungi under study

\begin{tabular}{|c|c|c|c|c|c|c|}
\hline \multirow{3}{*}{ Toxicity class } & \multicolumn{4}{|c|}{ Fungi species } & \multirow{2}{*}{\multicolumn{2}{|c|}{ Total }} \\
\hline & \multicolumn{2}{|c|}{ A. niger } & \multicolumn{2}{|c|}{ A. flavus } & & \\
\hline & $N_{2}$ & $\%$ & $N_{3}$ & $\%$ & $N_{2+3}$ & $\%$ \\
\hline no toxicity & 9 & 40.9 & 2 & 18.2 & 11 & 33.3 \\
\hline low & 8 & 36.4 & 5 & 45.5 & 13 & 39.4 \\
\hline moderate & 2 & 9.1 & 3 & 27.3 & 5 & 15.2 \\
\hline high & 3 & 13.6 & 1 & 9.1 & 4 & 12.1 \\
\hline Total & 22 & 100.0 & 11 & 100.0 & 33 & 100.0 \\
\hline
\end{tabular}

The values of the odds ratio (OR) and of the variance of the logarithm of the OR were calculated separately for each partial criterion, and on this basis the significance of the hypotheses $\mathrm{OR}=1$ was estimated with the ztest. Tables 4, 5, 6 and 7 show the used data and the results.

Description of Tables 4, 5, 6, 7:

$N_{1} \quad$ number of A. ochraceus fungi samples

$N_{2+3}$ - number of A. niger and A. flavus fungi samples

OR $\quad$ odds ratio $=(\mathrm{a} / \mathrm{c}) /(\mathrm{b} / \mathrm{d})=\mathrm{ad} / \mathrm{bc}$

$\ln (\mathrm{OR})$ - logarithm of the odds ratio OR

$\mathrm{V} \quad$ - variance of $\ln (\mathrm{OR})=1 / \mathrm{a}+1 / \mathrm{b}+1 / \mathrm{c}+1 / \mathrm{d}$

$\mathrm{p}-$ significance of the hypothesis $\mathrm{OR}=1$

Table 4. Odds ratios (OR) for the first partial criterion under study

\begin{tabular}{|c|c|c|c|c|c|c|}
\hline Toxicity class & $N_{1}$ & $N_{2+3}$ & OR & $\ln (\mathrm{OR})$ & $\mathrm{V}$ & $\mathrm{p}$ \\
\hline no toxicity & 2 & 11 & 0.15 & -1.87 & 0.67 & 0.04 \\
\hline low, moderate or high & 26 & 22 & - & - & - & - \\
\hline Total & 28 & 33 & - & - & - & - \\
\hline
\end{tabular}


Multi-criteria Ranking Under Pareto Inclusive Criterion of Preference...

Table 5. Odds ratios (OR) for the second partial criterion under study

\begin{tabular}{|c|c|c|c|c|c|c|}
\hline Toxicity class & $N_{1}$ & $N_{2+3}$ & OR & $\ln (\mathrm{OR})$ & $\mathrm{V}$ & $\mathrm{p}$ \\
\hline high toxicity & 11 & 4 & 4.69 & 1.55 & 0.43 & 0.04 \\
\hline no, low, or moderate & 17 & 29 & - & - & - & - \\
\hline Total & 28 & 33 & - & - & - & - \\
\hline
\end{tabular}

Table 6. Odds ratios (OR) for the third partial criterion under study

\begin{tabular}{|c|c|c|c|c|c|c|}
\hline Toxicity class & $N_{1}$ & $N_{2+3}$ & OR & $\ln (\mathrm{OR})$ & $\mathrm{V}$ & $\mathrm{p}$ \\
\hline low & 4 & 13 & 0.13 & -2.07 & 0.48 & 0.007 \\
\hline moderate or high & 22 & 9 & - & - & - & - \\
\hline Total & 26 & 22 & - & - & - & - \\
\hline
\end{tabular}

Table 7. Odds ratios (OR) for the forth partial criterion under study

\begin{tabular}{|l|c|c|c|c|c|c|}
\hline \multicolumn{1}{|c|}{ Toxicity class } & $N_{1}$ & $N_{2+3}$ & OR & $\ln (\mathrm{OR})$ & $\mathrm{V}$ & $\mathrm{p}$ \\
\hline moderate & 11 & 5 & 8.8 & 2.17 & 0.5 & 0.005 \\
\hline no or low & 6 & 24 & - & - & - & - \\
\hline \multicolumn{1}{|c|}{ Total } & 17 & 29 & - & - & - & - \\
\hline
\end{tabular}

\section{Discussion and Conclusions}

The toxicity of fungi is usually measured using a scale of several ranks. In scientific literature, these ranks are often weighted in such a way that for many species of fungi the discrete distribution of these conventional weights in random samples occurs seemingly quite close to a continuous normal distribution, which gives some justification for making comparisons 


\section{Agnieszka Gniadek, Izabela Chmiel, Maciej Górkiewicz}

between values of the mean toxicity by using popular parametric tests like t-tests and ANOVA (Gniadek, 2013). However, from a practical perspective, the mean weight of toxicity is not sufficient for assessing the potential risk to health created by fungi species. For instance, the inhalation of some fungi with lower mean values but with greater variance of toxicity can be considered as potentially more dangerous than inhalation of some other fungi with a greater mean toxicity, but with lower variance. Furthermore, in clinical practice, states of emergency and clinical interventions are complex in their nature (Campbell et al., 2000). They should be perceived rather as stochastic processes, rather than as sets of separated events (Gniadek, 2013). In light of this, in practice the ranks of toxicity are routinely grouped into only four conventional classes of toxicity: no toxicity, low toxicity, moderate toxicity, and high toxicity.

This study aims at demonstrating the usefulness of the Pareto inclusive criterion methodology for comparative analyses of fungi toxicity based on the identified distribution of the three fungi species under investigation A. ochraceus, A. niger, and A. flava - in the above conventional classes of toxicity. With this aim, the four partial criterions for detecting the worst sample were defined, a single criterion for each class of toxicity. In this study, the A. ochraceus fungi species was recognized as the most toxic species with regard to each partial criterion under consideration, with significance equal to $p=0.04, p=0.04, p=0.007$ and $p=0.005$, respectively. The above findings were supported with results of the chi-square test: it was proved that the distributions of the classes of toxicity were not equal $(p=0.004)$. The main limitation of this study is that it comprises a very small number of observations, the $N=61$ fungi samples only. For this reason, the statistical analyses made in this study should be considered only as an illustrative example of the proposed methodology.

The Pareto approach to the multi-criteria choice task has its recognized advantages. The Pareto inclusive criterion takes into account several partial criterions, but the procedure is based on multiple steps of pair-wise comparisons involving only a single partial criterion at each step. The relationships between the pairs of compared objects can be measured with use of any practicable method available at the moment. If the need arises, each partial criterion and each pair of objects can be evaluated in its specific way. At each pair-wise comparison, at least, the choice of a solution can be based only on intuition, common sense, or expert opinion. Thus, in its general formulation, the Pareto procedure can be considered as a useful metaheuristic only, aimed at imitating the natural process of looking for the best alternative, but not as a formal theory (Czyżak et al., 1998; Furems et al., 2003). 
Nevertheless, the whole procedure can be performed as a type of statistical inquiry, with use of the recognized formal methods only. Then, the Pareto approach does not require any ordering or weighting of used partial criteria. The final solution can be obtained without any intensive computations. It is quite robust to reject some criteria from consideration, and somewhat robust to include some new criteria (Zopounidis et al., 2002). However, from the practical point of view, it can be a very hard task to express and articulate the needed proper set of partial criteria of preferences (Brouwer et al., 1999; Korhonen et al., 1998). Moreover, the Pareto approach has its crucial weakness: in practice the worst object (or the best object) can very rarely be found using this method. The problem of continuation of the multi-criteria choice if the worst object (or the best object) cannot be found under the Pareto criterion was not included into the scope of this paper. Nevertheless, it should be noted that in such situations, the Pareto method offers some deeper insight into the relations between objects and partial criterions.

To conclude - the proposed method of multi-criteria ranking under the Pareto inclusive criterion of preference illustrated its utility in the case under study.

\section{R E F E R E N C E S}

Aziz, D. M. (2006). Assessment of bovine sperm viability by MTT reduction assay. Animal Reproduction Science, 92(1-2), 1-8.

Brouwer, W. B. F., \& Schut, F. T. (1999). Priority care for employees: A blessing in disguise? Health Economics, 8(1), 65-73.

Byun, J. W., Choo, S. H., Kim, H. H., Kim, Y. J., Hwang, Y. J., \& Kim, D. Y. (2008). Evaluation of boar sperm viability by MTT reduction assay in beltsville thawing solution extender. Asian-Australasian Journal of Animal Sciences, 21(4), 494-498.

Campbell, M., Fitzpatrick, R., Haines, A., Kinmonth, A. L., Sandercock, P., Spiegelhalter, D., \& Tyrer, P. (2000). Framework for design and evaluation of complex interventions to improve health. British Medical Journal, 321(7262), 694-696.

Czyżak, P., \& Jaszkiewicz, A. (1998). Pareto simulated annealing - a metaheuristic technique for multiple-objective combinatorial optimization. Journal of Multi-Criteria Decision Analysis, 7(1), 34-47.

Fernández, F. R., Nickel, S., Puerto, J., \& Rodríguez-Chía, A. M. (2001). Robustness in the Pareto-solutions for the multi-criteria minisum location problem. Journal of Multi-Criteria Decision Analysis, 10(4), 191-203. 


\section{Agnieszka Gniadek, Izabela Chmiel, Maciej Górkiewicz}

Furems, E. M., Larichev, O. I., Roizenson, G. V., Lotov, A. V., \& Miettinen, K. (2003). Human Behavior in a Multicriteria Choice Problem with Individual Task Different Difficulties. International Journal of Information Technology \& Decision Making, 2(1), 29-40.

Gareis, M. (1994). Cytotoxicity testing of samples originating from problem buildings. In E. Johanning \& C. S. Yang (Eds.), Fungi and bacteria in indoor air environments - health effects, detection and remediation (pp. 139-144). New York, USA: Eastern New York Occupational Health Program, Saratoga Springs.

Gniadek, A. (2012). Cytotoxicity of Aspergillus fungi as a potential infectious threat. In K. R. Priti (Ed.), Insight and Control of Infectious Disease in Global Scenario (pp. 231-248). Rijeka, Croatia: InTech.

Gniadek, A. (2013). Mykobiota środowisk pomieszczeń szpitalnych z uwzględnieniem cytotoksyczności grzybów z rodzaju Aspergillus (Rozprawa habilitacyjna). Kraków: Wydawnictwo FALL.

Gniadek, A., Macura, A. B., \& Górkiewicz, M. (2011). Cytotoxicity of Aspergillus fungi isolated from hospital environment. Polish Journal of Microbiology, 60(1), 59-63.

Gniadek, A, Macura, A. B., Twarużek, M., \& Grajewski, J. (2010). Cytotoxicity of Aspergillus strains isolated from the neonatal intensive care unit environment. Advances in Medical Sciences, 55(2), 242-249.

Korhonen, P., Phillips, J., Teich, J., \& Wallenius, J. (1998). Letter: Are Pareto Improvements Always Preferred by Negotiators? Journal of Multi-Criteria Decision Analysis, 7(1), 1-2.

Zopounidis, C., \& Doumpos, M. (2002). Multi-criteria decision aid in financial decision making: methodologies and literature review. Journal of Multi-Criteria Decision Analysis, 11(4-5), 167-186. 